This item was submitted to Loughborough's Research Repository by the author.

Items in Figshare are protected by copyright, with all rights reserved, unless otherwise indicated.

\title{
Where are we now? Twenty-five years of research, policy and practice on young carers
}

PLEASE CITE THE PUBLISHED VERSION

https://doi.org/10.1177/0261018317724525

PUBLISHER

SAGE $\odot$ The Author

VERSION

AM (Accepted Manuscript)

PUBLISHER STATEMENT

This work is made available according to the conditions of the Creative Commons Attribution-NonCommercialNoDerivatives 4.0 International (CC BY-NC-ND 4.0) licence. Full details of this licence are available at: https://creativecommons.org/licenses/by-nc-nd/4.0/

\section{LICENCE}

CC BY-NC-ND 4.0

\section{REPOSITORY RECORD}

Aldridge, Jo. 2017. "Where Are We Now? Twenty-five Years of Research, Policy and Practice on Young Carers". Loughborough University. https://hdl.handle.net/2134/25993. 


\section{Critical Social Policy}

Where are we now? Twenty-five years of research, policy and practice on young carers

Jo Aldridge*

*Jo Aldridge is Professor of Social Policy and Criminology, Department of Social Sciences. Loughborough University, UK

Email: J.Aldridge@lboro.ac.uk 


\section{Where are we now? Twenty-five years of research, policy and practice on young carers}

Jo Aldridge

\section{Abstract}

It is more than 25 years since the critical dialogue on young carers was played out in the pages of this journal (see Morris and Keith, 1995; Aldridge and Becker, 1996). Since that time, research evidence has given us a clearer picture of the extent of young caring in the UK and its consequences for children and families, including two new national studies that focus on the prevalence and impact of young caring in England. The introduction of the Care Act, 2014 and the Children and Families Act, 2014 also places new duties on professionals to identify and support young carers and their families. However, this increased focus, not only in policy and practice but also in terms of public awareness, has created a number of dilemmas and challenges for health and social care professionals, whose duty it is to identify and support young carers. These challenges, to a large extent, both mirror and advance issues raised in the original dialogue on young carers in the mid 1990s. They centre on the drive to generate data on the numbers of young carers to support policy directives and service delivery and, some have argued - in the current climate of serious fiscal retrenchment and cuts to youth services - on promoting the needs of one group of vulnerable children and young 
people over other groups of children in need. This commentary considers some of these challenges and dilemmas.

\section{Keywords}

Young carers; the Care Act, 2014; Children and Families Act, 2014; children first; 'moral crusade' 


\section{Challenges in estimating the prevalence of young carers}

Evidence relating to the numbers of young carers in England and Wales has, until recently, been based mainly on primary and secondary analysis of census survey data and also on purposive studies of children and young people already identified as young carers. Census data from 2011 showed there were just over 166,000 children in England and Wales under the age of 18 providing care for parents or other relatives in the home who were chronically sick or disabled (Office for National Statistics, 2013). In 2010 , however, a study conducted by the BBC estimated that there were 700,000 young carers in the UK. In 2014, partly as a result of these discrepancies in numbers and in order to inform the development of new legislative guidance, the Department for Education commissioned a suite of research that included both qualitative and quantitative methods to understand the prevalence and impact of young caring across England (see Aldridge, et al, 2016; Cheesbrough et al, 2017). This research included children between the ages of 5 and 17, including those not known to local authorities in the young carer literature these children are referred to as 'hidden' young carers. The drive to provide a clearer picture of the prevalence of young caring - to address the inconsistencies in the data - was much needed; despite more than 25 years of research and political and public awareness of the issue, in some cases 'guestimates' or false elevations of the numbers of young carers nationally have been made based on flawed and sometimes unreliable evidence with the result that young carers, as subgroup of vulnerable children in need, were presented as a growing social 'problem'. 
Studies on young carers to date (and the more recently introduced category of young adult carers) often use different definitions of young carers and include different age ranges of children and young people in their samples. For a number of years academics and researchers, as well a wide number of support organisations, referred to the Blackwell Encyclopaedia of Social Work (Becker, 2000: 378) definition of young caring which originated from the work of the Young Carers Research Group at Loughborough University:

Young carers are children and young people under the age of 18 who provide care, assistance or support to another family member. Young carers carry out, often on a regular basis, significant or substantial caring tasks and assume a level of responsibility, which would usually be associated with an adult. The person receiving care is often a parent, but can be a sibling, grandparent or other relative who is disabled, has some chronic illness, mental health problem or other condition connected with a need for care, support or supervision.

Increasingly, however, researchers and practitioners began to question the ambiguity of 'regular' and 'significant' as indicators of caring and attention shifted to considerations of the impact of caring on children's lives. Notably, the definition used in the latest national study of young carers (Cheesbrough et al, 2017: 6) removes reference to 'regular', 'significant' and 'substantial', includes recognition of the impact of caring on children and extends the location of caring activity beyond the family home. It is worth noting that, aside from age, few studies to date have focused on other specific dimensions or characteristics of young carer populations such as social class or ethnicity. Some studies have pointed to low income and poverty in families as 
determining factors in children taking on caring roles (see, for example, Children's Society, 2013; Ridge, 2009); and findings from a European study of BME young carers (Care2Work, 2017) showed that this group of young people face a number of challenges, including language and migration barriers as well as access to employment and support. What is particularly problematic about the European study, however, is that young carers are defined as young people 'under the age of 30' (p. 10).

Even in the UK, where considerable advances have been made in research, policy and practice on young carers, the age (and age range) of young carers varies considerably, particularly as a threshold indicator for service provision. What is notable is that organisations that work with young carers include different age ranges of children and young people both in their definitions (set out in mission statements, for example) and in their remit of support. So, while the 'under 18' distinction is an important one in much of the research and literature on young carers, a number of service providers in the UK work with older groups of young people and thus with broader age boundaries that may include, for example, children and young people aged 14-21 or 16-25. While these broader age ranges may, in the UK at least, now fall under the more recently introduced categorisation of 'young adult carer' (see Learning and Work Institute, 2016), the 'under 18' marker is both important and necessary because it recognises the status of the 'child' in a legal context, and thus makes clear where the duty of care and responsibility lies in recognising and supporting young carers' needs. In addition, one of the consequences of extending the 'under 18 years' age boundary in both research studies (see Care2Work, 2017) and in professional practice is that it may serve to falsely elevate estimates or assumed numbers of young carers nationally (and 
internationally), many of whom would not, in fact, fall under the category of 'child' (according to legal definitions).

Further problems with the prevalence data on young carers relate to the kinds of methods adopted in research studies on young carers and the instruments used to measure outcomes. The types of methods used should screen for young caring, that is, they should attempt to establish whether children are engaged in caring activities or not; they should also be sensitive to and attempt to gather first-hand data from children and young people themselves, as well as parents. Parents and children will often have different perspectives on caring and their experiences of family life when parents (or other relatives in the home) are affected by illness or disabilities, which is why it is important that studies capture the views of parents and their children (in the DfEcommissioned national studies of young carers both children and parents were included; see Aldridge, et al 2016; Cheesbrough, 2017). Furthermore, some parents may not describe their children as 'carers', or they may reject the 'carer' identity entirely.

The kinds of instruments used in some prevalence studies of young carers have not always been appropriate or rigorously applied. And yet, broad claims and generalisations about numbers are often made based on studies that use flawed or incompatible instruments. An example here is the 2010 BBC survey of school children, the findings from which are only available via a news item on the BBC website ('Number of child carers "four times" previous estimate', BBC, 2010), and on which it was claimed there were 'about 700,000' young carers in the UK. This estimate was based on one in 12 young carers identified from 4,029 schoolchildren surveyed. In the online news 
report, details of the methods used in the study refer to a questionnaire sent to pupils in just 10 schools across the UK in which questions were asked 'about both the levels of responsibility young people had in the home, and the types of caring activity they undertook'. Further enquiries of the BBC about the study revealed that the survey did not attempt to screen for young caring, rather the questions asked assumed a level of understanding by children about care provision and that they understood the distinction between caring about and caring for someone (personal correspondence between BBC reporter and Aldridge, 2010).

Leaving aside the fact that this would make it more likely that children's responses reported general household responsibilities common perhaps to many children (including those whose parents or other relatives in the home were not in need of care and support), identifying numbers of young carers from anonymised questionnaire surveys like this (that is, that fail to screen for caring) is never going to provide reliable prevalence data. This problem is mirrored in approaches that include questions on census surveys, where question length and numbers are inevitably limited and so capturing children's understanding of caring through these methods remains a significant challenge. Notably, in the national omnibus survey of young carers in England (Cheesbrough et al, 2017) 420 young carers were identified out of 79,629 households - giving a figure of just $0.5 \%$ young carers in the general population.

\section{Evidence of a 'moral crusade'?}

Despite both methodological and reliability problems with the BBC national survey, the 700,000 figure has been used widely since by campaign groups and in the media to 
highlight the extent of the young carer 'problem' (see, Carers Trust, 2015; The Guardian, 2014), suggesting evidence of what Weitzer (2007: 448) describes as a 'moral crusade'i - where social conditions are presented as 'problems' 'as a result of claims-making by interested parties, claims that may or may not reflect actual social arrangements'. A further example of this in contemporary young carer discourses and campaigning can be seen in the Children's Society's 2013 report of the national study of young carers, 'Hidden from view: The experiences of young carers in England' which, again, referred to the 700,000 prevalence figure. The report also stated that the census data from both 2001 and 2011 were 'likely to be an underrepresentation of the true picture as many remain under the radar of professionals.' (2013: 5; emphasis added). Despite not arriving at a prevalence figure for young caring nationally, the report posited that the 2011 census figure was, nevertheless, 'just the tip of the iceberg' (p. 4).

In some respects then elements of a 'moral crusade' are evident in contemporary young carer discourses, and in the lobbying and campaign activities on the part of some charities and third sector organisations that aim to generate public concern about young carers, and get politicians and governments to address the 'problem'. This is not to suggest wrongdoing or malpractice by these organisations. Evidence from research, including the latest national studies of young carers and their families, shows clearly that, without recognition or steps taken to prevent it, caring can seriously undermine children's self-esteem, have an adverse impact on their education and relationships with their peers and family, as well as their transitions into adulthood, especially when caring becomes long term and is disproportionate to children's age and level of maturity (see Abraham and Aldridge, 2010; Cheesbrough et al, 2017; Children's Commissioner 
for England, 2016); this issue was also debated in the pages of this journal in the mid 1990s - see Morris and Keith, 1995; Aldridge and Becker, 1996.

Furthermore, the upside of the lobbying and campaign work with and on behalf of young carers has been to raise awareness and recognition of the needs of children with caring responsibilities and to help provide support for them, especially when caring has a disproportionate and adverse effect on their childhoods. At the same time, however, promoting false estimates of the numbers of young carers and lobbying for the allocation of resources to support children in their caring roles, have meant a shift in focus away from early identification and intervention as preventive measures so that children do not have to care. It has also successfully diverted attention away from structural and systemic factors that increase the chances of children being drawn into inappropriate caring roles. Such factors include cuts to welfare support and the cumulative impact of austerity measures, low income, poverty (see Ridge, 2009), poor or ineffective services and so on.

Paradoxically, structural or systemic failings such as these also put further pressure on campaign groups and support organisations to elevate social issues (that, in turn, become social 'problems') or to over emphasise their importance in bid to secure funding in an increasingly competitive and under resourced market. Again, this is not to suggest wrongdoing by those organisations that have done so much work with and on behalf of young carers and their families, but it helps to explain (though not excuse) the impetus to elevate the numbers of young carers who need support. One of the more pervasive - and, as evidence has shown, also persuasive (see Aldridge and Becker, 
2003) - effects of this has been to accentuate children's caring responsibilities as a likely, sometimes even inevitable, outcome of living in families affected by parental illness or disability. In fact the need for children to provide care may be only one of the consequences for them of living in families where parents have health and social care needs that are not being adequately met through appropriate interventions, including whole family and parenting support. An outcome of this shift in emphasis has been to promote the needs of one group of vulnerable children over other groups who may, in fact, be in equal or even greater need of support. An example here is the 1 in 5 children who have been exposed to domestic violence and abuse and yet many of who still do not receive the support they need (see Radford et al, 2011).

It is possible that campaign groups and those who work in third sector support organisations make assumptions about higher numbers of young carers simply because they work with these children and young people on a daily basis, thus serving to heighten awareness of the issue as a significant social 'problem' (even if it does not, there is less opportunity for comparison with other vulnerable groups to lend some perspective in terms of numbers and outcomes). This, in turn, helps to sustain belief in the existence of large numbers of 'hidden' young carers in the general population who are not in receipt of support (but who are often presumed to be in the most need). While this supposition is not supported in evidence from the latest national study of young carers (see Aldridge et al, 2016), the 'hidden' paradigm has some utility for campaign groups and is also difficult to disprove. Not only are 'hidden' vulnerable populations hard to identify and 'count', there may also be justifiable reasons for them remaining unidentified and unaccounted for. A number of research studies on young 
carers and their families have shown consistently that fear of disclosure of caring is a significant factor in children's (and parents') reluctance to self-identify and/or seek help. This fear is often based on concerns about child protection or safeguarding decisions that may result in family separations. Evidence to date suggests that such concerns are far from unfounded. Data from 2015, for example, show that more than 2000 children were placed in care because of 'parents' illness or disability' (Zayed and Harker, 2015: 7).

However, evidence also shows that some families actively resist children being identified or 'labeled' as young carers because of the stigma associated with the term and also because it fails to address the real problem, which is that many families lack appropriate and effective family-based interventions that would prevent children from having to provide care in the first place (see Aldridge, et al, 2016).

\section{The policy context}

The Care Act 2014 places a duty on local authorities to identify young carers in their area. Indeed both the Care Act and the Children and Families Act, 2014 (CFA) (which amends the Children Act, 1989) make specific reference to young carers, focusing on their assessment, transitional (that is, from children's to adult services) and wider needs. However, the new legislation has also led to a degree of uncertainty, especially among adult services professionals, some of who remain unsure about screening and identification processes and may not consider children as part of their professional purview or remit (see Research in Practice, 2015). 
To date, strategies and mechanisms for assessing young carers' needs have varied in quality and consistency and effective screening protocols that would help professionals ascertain whether children are carers or not have largely been missing (an exception here is the recent introduction of the YC-QST-20 screening tool, the questions from which were cognitively tested as part of the national study of young carers; see Young Carers Research Group, 2017; Aldridge, et al, 2016; Cheesbrough et al, 2017). This, coupled with a lack of understanding among some professionals about the triggers for young caring and the wider needs of children and families affected by parental illness or disability, have resulted in inconsistent identification and support interventions (see Aldridge, et al, 2016; Children's Commissioner for England, 2016). One of the outcomes of this has been the inappropriate referral of children to young carer services, and especially in the absence of alternative sources of support. A common refrain from a number of young carers projects over the years has been that they become a 'dumping ground' for children who, despite assessment outcomes, cannot be supported elsewhere and more appropriately because youth services are simply not available (according to a report by Unison (2016), for example, cuts in youth services spending since 2010 have amounted to $€ 387 \mathrm{~m})$.

\section{Young carers are children first}

In terms of assessment, the CFA is helpful in recognising young carers' additional needs and in requiring professionals to ascertain children's views and wishes about caring, their wider needs and to consider preventive strategies. Guidance for professionals 
following the introduction of both the CFA and the Care Act, 2014, for example, states that young carers' needs assessments should, 'recognize that each child is a unique person on their own journey to adulthood and maturity,' and that local authorities should, 'offer services to promote their welfare as a child in need' (Children's Society, Directors of Adult Social Services, ADCS and Carers Trust, 2015; emphasis added).

Early identification of children's caring responsibilities and wider needs (as children in need) should also prevent caring from becoming onerous to the point of adversely affecting their lives and transitions into adulthood. Where this does not occur, and where caring becomes long term, children are more likely to experience psychological and emotional problems such as low self-esteem and anxiety-related disorders. Research that used psychological measures to gauge the impact of caring on children and young people, for example, showed that children who care for longer than two years are more likely to experience negative outcomes in terms of their emotional and mental health (see Abraham and Aldridge, 2010).

Early interventions in families affected by parental illness or disability should not only include assessments of children's needs but also the parenting needs of adults. For health and social care professionals this means recognizing the triggers for young caring - factors such as lone parenthood, unemployment, low income, lack of informal support mechanisms - asking whether children are taking on inappropriate caring responsibilities in the home and what additional needs adult patients/service users may have as parents (see Carers Trust, 2014; Falkov, 2013). Without this and without the kinds of interventions that recognize and address the needs of children and parents 
using whole family approaches, children are likely to take on, and continue in, inappropriate caring roles.

\section{In summary}

Over the past 25 years there have been a number of important advances in research, policy and practice regarding the needs of children with caring responsibilities and their families, especially in the UK. These include greater recognition of children's caring roles and the impact of these on their lives, and those of their families, as well as the need for interventions and support that are based on whole family approaches. Policy changes and new legislation have also resulted in greater recognition of children's need for support both as carers and as children in need. Recent national evidence has shown, however, that despite these changes, young carers' needs assessments are still inconsistently applied and lack rigorous screening procedures to help professionals identify young carers more consistently, and in order to facilitate early interventions that would prevent children taking on inappropriate caring roles long term.

Globally, and in a comparative context, we know much less about children's experiences of living in families affected by parental illness or disability and about expectations of caring in different cultural contexts, although research by Robson and others in subSaharan Africa has made important contributions to the emerging international comparative literature on young carers (Robson et al, 2006; see also Becker, 2007; Robson, 2000). European wide research conducted by the IARS International Institute 
in 2017 concluded, however, that with respect to BME young carers, they 'constitute one of the most, if not the most, marginalised and neglected groups by policy makers'. Evidence to date has shown that young caring is often a gendered activity, but further research is also needed about the impact of gender on children's caring roles and on their transitions into adulthood. These gaps in knowledge and understanding about the experiences and needs of children living in families affected by illness or disability need to be addressed through further research, through policy development and models of good practice that draw on international and comparative evidence based on research with children and families themselves. 


\section{References:}

Abraham K and Aldridge J (2010) The mental well-being of young carers in Manchester. Young Carers Research Group with Manchester Carers Forum and Child and Adolescent Mental Health Services (CAMHS), Manchester.

Aldridge J and Becker S (2003) Children caring for parents with mental illness: perspectives of young carers, parents and professionals. Bristol, UK: The Policy Press.

Aldridge J and Becker S (1996) Disability rights and the denial of young carers: the dangers of zero sum arguments. Critical Social Policy 48 (16): 55-76.

Aldridge J, Clay D, Connors C, Day N and Gkiza M (2016) The lives of young carers in England: qualitative report to Department for Education:

https://www.gov.uk/government/uploads/system/uploads/attachment data/file/498 115/DFE-RR499 The lives of young carers in England.pdf

Becker S (2007) Global perspectives on children's unpaid caregiving in the family research and policy on 'young carers' in the UK, Australia, the USA and Sub-Saharan Africa. Global social policy 7(1): 23-50. 
Becker S (2000) Young carers. In: Davies M (ed.) The Blackwell encyclopaedia of social work. Oxford: Blackwell.

BBC (2010) Number of child carers 'four times previous estimate':

http://www.bbc.co.uk/news/education-11757907

Care2Work (2017) Tearing down barriers to employment and education for young, black and minority ethnic carers. London: IARS Publications.

Carers Trust (2014) Whole family approach - practice examples:

https://professionals.carers.org/whole-family-approach-practice-examples

Carers Trust (2015) Key facts about carers and the people they care for: https://carers.org/about-caring

Cheesbrough S, Harding C, Webster H, Taylor L and Aldridge J (2017) The lives of young carers in England: omnibus survey report, January, 2017. Department for Education: https://www.gov.uk/government/uploads/system/uploads/attachment data/file/582 575/Lives of young carers in England Omnibus research report.pdf 
The Children's Commissioner for England (2016) Young carers: the support provided to young carers in England. Office of the Children's Commissioner:

http://www.childrenscommissioner.gov.uk/sites/default/files/publications/Young\%2 0Carers\%20report\%20December\%202016.pdf

The Children's Society (2013) Hidden from view: the experiences of young carers in England. Winchester: The Children's Society.

The Children's Society, Directors of Adult Social Services, ADCS and Carers Trust (2015) Young carers needs assessments:

$\underline{\text { www.londoncp.co.uk/files/young carers needs assess.pdf }}$

Falkov, A. (2013) The family model: Managing the impact of parental mental health on children. London: Pavilion.

The Guardian (2014) Hidden army of young carers to be uncovered under new legislation: https://www.theguardian.com/society/2014/nov/11/hidden-young-carers-get-break$\underline{\text { new-legislation }}$ 
HM Government (2014) The Care Act, 2014:

http://www.legislation.gov.uk/ukpga/2014/23/contents/enacted

HM Government (2014) Children and Families Act, 2014:

http://www.legislation.gov.uk/ukpga/2014/6/contents/enacted

HM Government (2015) The young carers (needs assessments) regulations, 2015: http://www.legislation.gov.uk/uksi/2015/527/pdfs/uksi_20150527_en.pdf

IARS International Institute (2017) BME young carers: One of the most neglected groups: http://www.iars.org.uk/content/BMEcarers

Learning and Work Institute (2016) Young adult carers:

http://www.learningandwork.org.uk/our-work/life-and-society/citizenscurriculum/young-adult-carers

Morris J and Keith L (1995) Easy targets: a disability rights perspective on the "children as carers" debate. Critical Social Policy 44/45: 36-57. 
Office for National Statistics (2013) 2011 Census analysis: unpaid care in England and Wales:

https://www.ons.gov.uk/peoplepopulationandcommunity/healthandsocialcare/health caresystem/articles/2011censusanalysisunpaidcareinenglandandwales2011andcompa risonwith2001/2013-02-15

Radford L, Corral S, Bradley C, Fisher H, Bassett C, Howat N and Collishaw S (2011) Child abuse and neglect in the UK today. London: NSPCC.

Research in Practice (2015) Working with young carers - a whole family approach to assessment. Knowledge Exchange Webinar:

https://www.rip.org.uk/resources/webinar-recordings/working-with-young-carers-awhole-family-approach-to-assessment-knowledge-exchange-webinar/

Ridge T (2009) Living with poverty. Research Report 594. London: Department for Work and Pensions. 
Robson E (2000) Invisible carers: young people in Zimbabwe's home-based healthcare. Area 32 (1): 59-69.

Robson E, Ansell N, Huber U S, Gould W T, \& van Blerk L (2006) Young caregivers in the context of the HIV/AIDS pandemic in sub-Saharan Africa. Population, Space and Place 12(2): 93-111.

Unison (2016) The damage: A future at risk: Cuts in youth services. London: Unison.

Weitzer R (2007) The social construction of sex trafficking: ideology and institutionalization of a moral crusade. Politics \& Society 35(3): 447-475.

Young Carers Research Group (2017) YC-QST-20:

http://www.ycrg.org.uk/youngCarersDownload/YCRG\%20questionnaire.pdf;

Zayed Y and Harker R (2015) Children in care in England: Statistics. Briefing paper 04470. London: House of Commons Library. 